\title{
OBTENÇÃO DE BIODESEL A PARTIR DO ÓLEO DE SOJA UTILIZANDO A VERMICULITA EXPANDIDA
}

\author{
V. C. SILVA ${ }^{1}$, J. S. ALBUQUERQUE ${ }^{1}$ e B. V. SOUSA ${ }^{1}$ \\ ${ }^{1}$ Universidade Federal de Campina Grande, Departamento de Engenharia Química \\ E-mail: valdetecampossilva@hotmail.com, jonassantana25@gmail.com,
}

bianca@deq.ufcg.edu.br

\begin{abstract}
RESUMO - A utilização do biodiesel representa atualmente uma alternativa promissora na redução de impactos ambientais e fonte estratégica de energia renovável. Sua produção é baseada na transesterificação de óleos vegetais ou gorduras animais, utilizando catalisadores homogêneos ou heterogêneos. Os catalisadores argilosos vêm ganhando destaque, por apresentarem acidez, alta capacidade de troca catiônica e abundância na forma in natura. Geralmente, realizam-se modificações na argila vermiculita por tratamentos térmicos, os quais aumentam a distância entre os espaços lamelares e favorecem o processo catalítico. O objetivo desse trabalho é avaliar o desempenho da vermiculita expandida na reação de transesterificação do óleo de soja. Através das micrografias e dos infravermelhos observou-se folhedos espaçosos e delaminados e confirmou-se a ausência de bandas características de água após a expansão, respectivamente. Verificou-se que a vermiculita expandida apresentou potencial catalítico para utilização na rota metílica de produção de biodiesel.
\end{abstract}

\section{INTRODUÇÃO}

O mineral vermiculita é um silicato composto principalmente de ferro, alumínio e cálcio. Pertencente à família das micas, ele existe em abundância no Brasil, com reservas no Piauí, Goiás, Paraíba e na Bahia. A vermiculita tem massa específica baixa e apresenta forma de lâmina (lamelar). Sua principal vantagem é ser um material inorgânico e resistente a temperaturas elevadas.

Quando aquecida a uma temperatura superior a $150{ }^{\circ} \mathrm{C}$, a vermiculita aumenta de volume, expande-se perpendicularmente (como uma sanfona) e libera água, aumentando seu volume até 20 vezes. Como a maioria dos minerais, a vermiculita é hidrofílica, ou seja, atrai moléculas de água e pode ser molhada. Poucos minerais são hidrófobos, como enxofre, grafite e carvão que, quando mergulhados na água, não molham e saem secos (Martins, 2000).

O biodiesel é um combustível biodegradável e renovável, consistindo de ésteres monoalquílicos de ácidos graxos preparados a partir de matérias-primas contendo triglicerídeos, tais como óleos vegetais, gordura animal e resíduos (García-Sancho, 2011).

A reação de transesterificação é considerada o processo químico mais viável, no momento, em todo o mundo para a produção do biodiesel, principalmente porque as 
características físicas dos ésteres de ácidos graxos são muito próximas daquelas do diesel (Geris et. al., 2007; Candeia, 2008).

A transesterificação, também chamada de alcoólise, é a reação de um óleo ou gordura com um álcool para formar os ésteres e glicerol. A estrutura da sua reação está ilustrada na Figura 1 (Singh e Sarma, 2011).

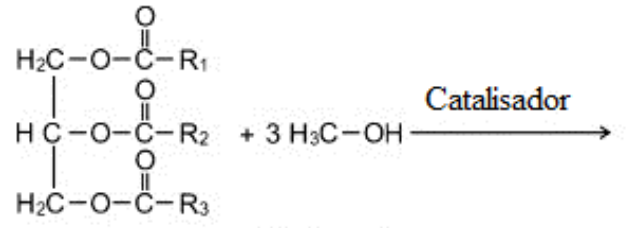

Triglicerideo Metanol<smiles>[R]C(=O)OC([R])(OC)OC([R])=O</smiles>

Ésteres metilicos Glicerol

Figura 1 - Reação de transesterificação com metanol na presença de catalisador.

Atualmente, o biodiesel é normalmente produzido usando um catalisador básico homogêneo. Os mais utilizados são o hidróxido de sódio $(\mathrm{NaOH})$ e o hidróxido de potássio (KOH), que são facilmente solúveis no metanol (Felizardo et al., 2006; Kulkarni et al., 2006). A vantagem deste processo é a produção de ésteres metílicos, a obtenção de rendimentos muito elevados em condições suaves e que a reação geralmente leva pouco tempo para a sua execução (Sharma et al., 2006; Meher et al., 2006).

Este trabalho tem como objetivo a reação de transesterificação do óleo de soja com o álcool metílico, utilizando como catalisador heterogêneo a vermiculita expandida e, avaliar a capacidade de conversão em ésteres.

\section{METODOLOGIA}

\subsection{Expansão da vermiculita in natura}

Inicialmente, $20 \mathrm{~g}$ de argila vermiculita passada em peneira Tyler de $200 \mathrm{mesh}$, foi pesada e depois medido o volume em uma proveta graduada. Posteriormente, foi adicionada, com elevado grau de espalhamento, em cadinhos de porcelana, que foram levados a forno mufla por 15 min à temperatura de $800{ }^{\circ} \mathrm{C}$ para promover a secagem. Levou-se ao dessecador, até ficar na temperatura ambiente, aproximadamente meia hora. Em seguida, mediu-se, com a mesma proveta graduada, o grau de expansão (GE), definido como a razão entre o volume da vermiculita expandida e in natura. Através da Equação 1 foi calculado o GE:

$$
G E=\frac{V_{\text {exp }}}{V_{\text {in }}}
$$




\subsection{Produção de biodiesel}

A argila vermiculita expandida foi testada na reação de transesterificação metílica do óleo de soja utilizando um reator PAAR modelo 4848, de alta pressão, do tipo batelada. $\mathrm{Na}$ Tabela 1 estão apresentadas as condições.

Tabela 1- Condições de operação da reação de transesterificação metílica

\begin{tabular}{|c|c|}
\hline Variáveis & Condições \\
\hline Óleo/Álcool (molar) & $1: 10$ \\
\hline Catalisador $(\mathrm{m} / \mathrm{m})$ & $4 \%$ \\
\hline Pressão & Autógena \\
\hline Rotação $(\mathrm{rpm})$ & 500 \\
\hline
\end{tabular}

A temperatura e o tempo de reação estão descritos na Tabela 2.

Tabela 2 - Condições de operação da reação de transesterificação metílica para as amostras

\begin{tabular}{|c|c|c|}
\hline & Tempo de reação (h) & Temperatura $\left({ }^{\circ} \mathbf{C}\right)$ \\
\hline Amostra 1 & 4 & 100 \\
\hline Amostra 2 & 2 & 100 \\
\hline
\end{tabular}

Inicialmente, misturou-se o óleo de soja, o metanol e o catalisador no reator, este foi fechado com segurança, ajustado para as condições de operação e, então, se deu início à reação de transesterificação. Após o tempo reacional, a mistura foi colocada em funil de decantação e deixada em repouso até que houvesse a completa separação das fases da mistura. Posteriormente, a fase mais densa (a glicerina) foi retirada, restando apenas o biodiesel. Em seguida, foi realizada a etapa de lavagem do biodiesel, onde adicionou-se água deionizada. A lavagem ocorreu até que a água estivesse neutra. Finalmente, o material obtido foi colocado em estufa durante $2 \mathrm{~h}$ a $100{ }^{\circ} \mathrm{C}$ para retirada da água. Após esta etapa, o biodiesel foi encaminhado para análises.

\subsection{Micrografia Eletrônica de Varredura (MEV)}

As argilas foram analisadas em um Microscópio Eletrônico de Varredura da PHILIPS XL30FEG (Field Emission Source) com um Espectrofotômetro de energia dissipativa acoplado.

\subsection{Espectrofotometria na Região do Infravermelho (FTIR)}

As análises foram realizadas pelo método do pó utilizando um espectrofotômetro de infravermelho AVATAR TM 360 ESP FT-IR, com comprimentos de onda na faixa de 2000 a $650 \mathrm{~cm}^{-1}$, com incrementos de $500 \mathrm{~cm}^{-1}$ e resolução de $4 \mathrm{~cm}^{-1}$. 


\subsection{Teste catalítico: Reação de transesterificação}

A análise por cromatografia gasosa foi realizada para determinação dos percentuais de ésteres metílicos de ácidos graxos nas amostras de biodiesel. Uma amostra da solução é inserida no injetor do equipamento, vaporizada e transportada por um gás de arraste através da coluna cromatográfica, onde ocorre a separação da mistura. As substâncias separadas saem da coluna dissolvida no gás de arraste e passam por um detector, que gera um sinal elétrico proporcional à quantidade de material diluído. $\mathrm{O}$ biodiesel foi analisado num cromatógrafo a gás da marca VARIAN, modelo 450-GC.

\section{RESULTADOS E DISCUSSÃO}

\subsection{Expansão da vermiculita in natura}

Os resultados do grau de expansão da vermiculita in natura encontram-se na Tabela 3.

Tabela 3 - Resultados do grau de expansão (GE)

\begin{tabular}{|c|c|c|c|c|c|}
\hline Temperatura $\left({ }^{\circ} \mathrm{C}\right)$ & $\operatorname{Min}(\mathrm{g})$ & $\operatorname{Mexp}(\mathrm{g})$ & Vin $(\mathrm{mL})$ & Vexp $(\mathrm{mL})$ & GE \\
\hline 800 & 25,6760 & 23,3632 & 37,0 & 42,0 & $\mathbf{1 , 1 3 5 1}$ \\
\hline
\end{tabular}

Legenda: $\mathrm{M}_{\mathrm{in}}=$ massa in natura, $\mathrm{M}_{\exp }=$ massa expandida, $\mathrm{V}_{\mathrm{in}}=$ volume in natura, $\mathrm{V}_{\mathrm{exp}}=$ volume expandido.

A água interlamelar, quando retirada pelo aquecimento, faz com que o argilomineral se expanda e, consequentemente, tem-se um aumento da sua área superficial. Na Tabela 3, observouse o aumento do volume da vermiculita com a diminuição da massa, devido à evaporação de água. Valores de GE acima de 1,0 são considerados bons resultados de expansão (França e Luz, 2002).

\subsection{Micrografia Eletrônica de Varredura (MEV)}

Na Figura 2 estão apresentadas as micrografias das vermiculitas in natura e expandida. 


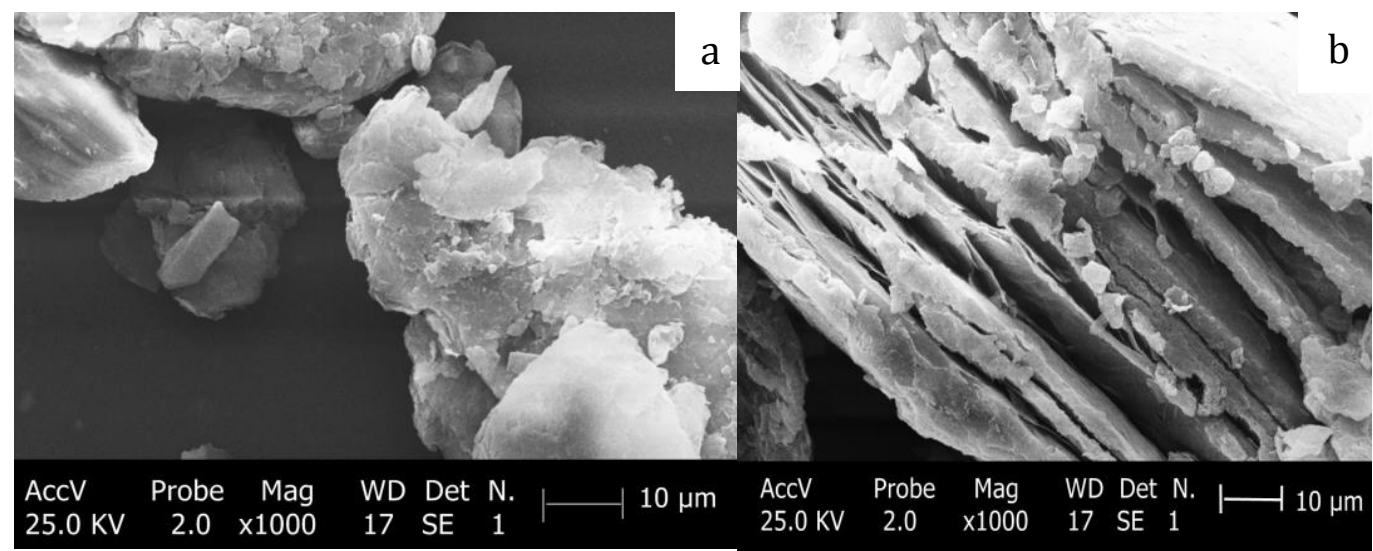

Figura 2- a) vermiculita in natura e b) vermiculita expandida.

Por meio de observações diretas das micrografias da vermiculita in natura (Figura 2a), observou-se uma estrutura compactada e escamosa, formada por aglomerados e pequenos espaçamentos, típica da argila vermiculita no estado natural. Nas micrografias da vermiculita expandida (Figura 2b) observou-se uma estrutura escamosa e menos compactada, com folhas bem delaminadas e aumento do espaçamento interlamelar do material. A expansão em altas temperaturas ocasiona a eliminação de água adsorvida no material. Logo, os espaçamentos entre as camadas interlamelares aumentam expressivamente e isso possibilita que outras moléculas difundam para o seu interior e incorporem em sua estrutura, podendo ser aplicado para a adsorção de materiais contaminantes e reações catalíticas.

\subsection{Espectrofotometria na região do infravermelho (FTIR)}

Na Figura 3 estão apresentados os resultados de espectrofotometria na região do infravermelho para a vermiculita in natura e expandida.

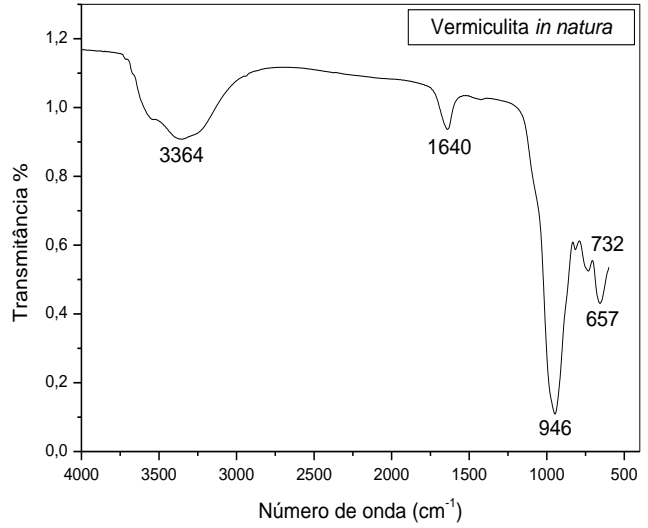

(a)

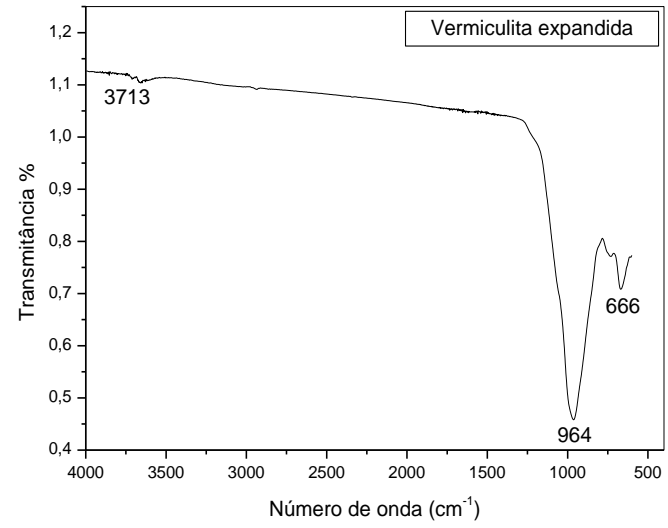

(b)

Figura 3 - Espectrofotometria na região do infravermelho para a vermiculita in natura (a) e expandida (b). 
Para vermiculita in natura, Figura 3a, observou-se uma banda de absorção larga e intensa na região de $3364 \mathrm{~cm}^{-1}$ referente a vibrações de deformação axiais de $\mathrm{O}-\mathrm{H}$ livres dos grupos silanóis $(\mathrm{SiOH})$ da estrutura, além de moléculas de água que são invariavelmente adsorvidas por ligações de hidrogênio e, também, encontradas na região interlamelar. Outra banda de intensidade média em $1640 \mathrm{~cm}^{-1}$ é atribuída à deformação angular simétrica da ligação O-H de água, confirmando a presença deste composto na estrutura.

$\mathrm{Na}$ Figura 3b, essas duas bandas não aparecem devido à eliminação de água no processo de expansão. Uma banda de intensidade forte é observada em $946 \mathrm{~cm}^{-1}$ e $964 \mathrm{~cm}^{-1}$, referente a estiramento assimétrico de $\mathrm{Si}-\mathrm{O}-\mathrm{Si}$ e $\mathrm{Si}-\mathrm{O}-\mathrm{Al}$ das lamelas tetraédricas e octaédricas. Duas bandas de intensidade fraca são observadas em $732 \mathrm{~cm}^{-1}$ e $657 \mathrm{~cm}^{-1}$ (Figura 3a) e uma em 666 $\mathrm{cm}^{-1}$ (Figura 3b) referentes as vibrações de deformação Al-OH e Al-O, respectivamente.

\subsection{Teste Catalítico: Reação de Transesterificação}

$\mathrm{Na}$ Tabela 4 estão apresentados os resultados de conversão para a reação de transesterificação.

Tabela 4 - Resultados de conversão da reação de transesterificação

\begin{tabular}{|c|c|c|}
\hline \multirow{2}{*}{} & \multicolumn{2}{|c|}{ Conversão (\%) } \\
\cline { 2 - 3 } & $2 \mathrm{~h}$ & $4 \mathrm{~h}$ \\
\hline Éster & $\mathbf{7 4 , 3 4}$ & $\mathbf{1 5 , 2 5}$ \\
\hline Monoglicerídeos & 0,00 & 0,00 \\
\hline Diglicerídeos & 25,66 & 7,15 \\
\hline Triglicerídeos & 0,00 & 77,60 \\
\hline Total & 100,00 & 100,00 \\
\hline
\end{tabular}

A partir dos dados apresentados na Tabela 4, verificou-se que a reação conduzida em tempo menor ( 2 horas), utilizando como catalisador a vermiculita expandida, apresentou um uma conversão de ésteres $(74,34 \%)$. Por outro lado, para as reações conduzidas em tempo maior $(4 \mathrm{~h})$, houve uma diminuição na conversão de ésteres para $15,25 \%$. O tempo de contato entre a emulsão formada pelo óleo com o metanol e a glicerina provavelmente favoreceu o processo de adsorção das espécies formadas e não reagidas nos espaçamentos interlamelares da vermiculita.

\section{CONCLUSÕES}

Através das análises de espectrofotometria na região do infravermelho, confirmou-se a ausência das bandas que caracterizam água na vermiculita expandida. Através das micrografias, observou-se o aumento dos espaçamentos interlamelares, com folhas bem delaminadas. O GE foi considerado satisfatório, uma vez que o seu resultado foi maior que 1 
e, em decorrência disso, observou-se um aumento expressivo no volume do material em função da diminuição da massa. A melhor condição de operação foi no tempo de $2 \mathrm{~h}$ de reação, apresentando uma conversão de $74,34 \%$ de ésteres.

\section{AGRADECIMENTOS}

Os autores deste trabalho agradecem à CAPES/PET/DEQ/UFCG.

\section{REFERÊNCIAS}

GARCIA-SANCHO， C.; MORENO-TOST, R.;. MÉRIDA-ROBLES， J. M.; GONZÁLEZ S. M.; J.; JIMÉNEZ-LÓPEZ, A.; MAIRELES-TORRES, P. Niobiumcontaining MCM-41 silica catalysts for biodiesel production. Appl Catal B-Environ, v. 108109, p. 161-167, 2011.

GERIS, R.; SANTOS, N. A. C.; AMARAL, B. A.; MAIA, I. S., CASTRO, V. D.; CARVAlHO, J. R. M.; Biodiesel de Soja - Reação de Transesterificação para Aulas Práticas de Química Orgânica. Quim Nova, vol. 30, n. 5, p. 1369-1373, 2007.

FELIZARDO, P.; NEIVA, C. M. J.; RAPOSO, I.; MENDES, J. F.; BERKEMEIER, R.; BORDADO, J. M. Production of biodiesel from waste frying oils. Waste Manage, v. 26, p. 487-494, 2006.

FRANÇA, S. C. A.; LUZ, A. B. Utilização da vermiculita como adsorvente de compostos orgânicos poluentes da indústria do petróleo. In: XIX Encontro Nacional de Tratamento de Minérios e Metalurgia Extrativa. p. 547-553, Recife. 2002.

KULKARNI, M. G.; DALAI, A. K. Waste cooking oil - an economical source for biodiesel: a review. Ind Eng Chem Res, v. 45, p. 2901-2913, 2006.

MEHER, L. C.; SAGER, D. V.; NAIK, S. N. Technical aspects of biodiesel production by transesterification - a review. Renew Sust Energ Rev, v. 10, p. 248-268, 2006.

MARTINS, J.; Vermiculita é transformada em mineral hidrofóbico, por Mara Figueira, Ciência Hoje, Jornal do Brasil, Rio de Janeiro - RJ, 09/08/00.

SARMA, A. K.; SARMAH, J. K.; BARBORA, L.; KALITA, P.; CHATTERJEE, S.; MAHANTA, P. et al. Recent inventions in biodiesel production and processing: a review. Recent Patent Eng, 2008, p.58. 
SHARMA, Y. C.; SINGH, B.; KORSTAD, J. Latest developments on application of heterogenous basic catalysts for an efficient and ecofriendly synthesis of biodiesel: a review. Fuel, v. 90, p. 1309-1324, 2011.

SINGH CHOUHAN, A. P.; SARMA, A. K. Modern heterogeneous catalysts for biodiesel production: A comprehensive review. Renew Sust Energ Rev, v. 15 p. 4378-4399, 2011. 